\title{
Expression of Stat3 and Notch1 is associated with cisplatin resistance in head and neck squamous cell carcinoma
}

\author{
FENG GU $^{1 *}$, YONGJIE MA ${ }^{2 *}$, ZUPING ZHANG ${ }^{3}$, JINGHUI ZHAO $^{3}$, \\ HISAYUKI KOBAYASHI ${ }^{4}$, LUN ZHANG ${ }^{3}$ and $\mathrm{LI} \mathrm{FU}^{1}$ \\ ${ }^{1}$ Department of Breast Pathology, ${ }^{2}$ Central Laboratory of Oncology Department, ${ }^{3}$ Department of Head and Neck, \\ Tianjin Medical University Cancer Institute and Hospital, Key Laboratory of Breast Cancer Prevention and Therapy \\ of the Ministry of Education, Key Laboratory of Cancer Prevention and Therapy of Tianjin, P.R. China; \\ ${ }^{4}$ Nitta Gelatin Incorporation, Osaka, Japan
}

Received September 7, 2009; Accepted October 27, 2009

DOI: 10.3892/or_00000683

\begin{abstract}
Cisplatin is the most important chemotherapeutic agent involved in treatment of head and neck squamous cell carcinoma (HNSCC), but cisplatin resistance in HNSCC is still a serious problem in clinic. The reasons why patients fail chemotherapy are unclear. We examined 25 HNSCC patients who were all tested for cisplatin sensitivity by CD-DST (collagen gel droplet embedded culture-drug sensitivity) method and expression of Stat 3 and Notch1. We found that high expression levels of Stat 3 and Notch1 were closely associated with cisplatin resistance respectively $(\mathrm{P}=0.014$, $\mathrm{P}=0.000)$. In addition, cisplatin resistance of HNSCC was decreased after inhibition of Stat 3 or Notch signaling in vitro. Our results provide first evidence that both high Stat 3 and Notch1 expression are associated with cisplatin resistance in HNSCC patients, supporting the hypothesis that coactivation of Stat 3 and Notch1 by their crosstalk induces the reprogrammed survival pathways in HNSCC responding to chemotherapy.
\end{abstract}

\section{Introduction}

Cisplatin was introduced for treatment of head and neck squamous carcinoma (HNSCC) since the early 1980s and 30 to $40 \%$ of complete response rates were reported $(1,2)$. Although cisplatin, as the most important chemotherapy agent for HNSCC, there were still nearly 70 to $80 \%$ of

Correspondence to: Dr Li Fu, Department of Breast Pathology, or Dr Lun Zhang, Department of Head and Neck, Tianjin Medical University Cancer Institute and Hospital, Huanhuxi Road, Tiyuanbei, Hexi, Tianjin 300060, P.R. China

E-mail: yongjiemagu@yahoo.com.cn

E-mail: fenggumayo@yahoo.com.cn

*Contributed equally

Key words: cisplatin resistance, head and neck squamous cell carcinoma, Stat3, Notch1 patients treated for relapsed or recurrent disease showing no response $(3,4)$. The reasons of patients failing chemotherapy are unclear. Cisplatin resistance in HNSCC may be mediated by a number of different mechanisms, including drug detoxification, up-regulation of DNA repair enzymes, gene amplification or the overexpression of gene products that provide a tumor cell with survival advance relative to normal cells (5).

Stat3 protein is a cytoplasmic transcription factor that translocates into the nucleus following cytokine activation (6-8), it has important roles in several biological responses such as proliferation, differentiation and apoptosis (9-11). Increasing studies have suggested that Stat 3 oncogenic pathway is associated with intrinsic drug resistance. Activation of Stat3 has been shown to confer resistance to Fas-mediated apoptosis in multiple myeloma and liver cancer $(12,13)$. Paclitaxel resistant ovarian cancer cells showed abnormal increase of Stat3 activity and the RNAi-mediated down-regulation of the transcription factor reduced paclitaxel resistance (14). In chronic myelogenous leukemia, imatinib mesylate-resistant cells became sensitive to the combination of flavopiridol and bortezomib, and were linked with the inactivation of Stat3 (15). It seems that Stat 3 signaling pathway acts as a predictive marker of drug resistance (16).

According to Kamakura et al and our previous studies, there is cross-talk between Notch pathway and Stat3 signaling $(17,18)$. Notch1 signaling related with chemoresistance has been reported in different kinds of tumor cells. Nefedova et al indicated that Notch1, but not Notch2 resulted in protection of myeloma and malignant lymphoid cells from melphalanand mitoxantrone-induced apoptosis. This protection is associated with up-regulation of p21 and growth inhibition of cells (19). Inhibition of Notch1 signaling also prevented bone marrow-mediated drug resistance and sensitized myeloma cells to chemotherapy (20). Our previous study also showed that there was higher expression of Notch1 in cisplatin resistance HNSCC compared with cisplatin-sensitive cases (21). Few studies have reported both Stat 3 and Notch1 expression related with HNSCC chemoresistance. The aim of this study was to characterize the association of Stat3, Notch1 expression with cisplatin resistance in HNSCC. 
In our present study, we chose 25 HNSCC patients who were all tested for cisplatin sensitivity by CD-DST (collagen gel droplet embedded culture-drug sensitivity) method. We found that the high expression levels of Stat3 and Notch1 were closely associated with cisplatin resistance. In addition, by inhibition of Stat 3 and Notch1 signaling, respectively, in HNSCC cells, the cisplatin sensitivity was significantly elevated. Thus, our study suggests that Stat 3 and Notch 1 may be candidate molecules for potential therapeutic targets in HNSCC cisplatin resistance.

\section{Materials and methods}

Patients. Twenty-five HNSCC patients were selected from the outpatients of Department of Head and Neck Carcinoma, Tianjin Medical University Cancer Institute and Hospital during the period of January 2007 to May of 2008. None of the patients had received chemotherapy before hospitalization. The tumors originated from the oral cavity $(n=10)$, hypopharynx $(n=7)$ and larynx $(n=8)$. Nineteen patients had stage 2 HNSCC and the remaining 6 patients had stage 3 or 4 HNSCC. Two of the patients were women and 23 were men. The median age was 50 years (range: 44-74). The specimens from the operations were divided into two pieces, one for histopathological and immunohistochemical examination and one for CD-DST analysis. Participation of the patients in the clinical part of the study was approved by the Ethics Committee, Tianjin Medical University Cancer Institute and Hospital.

Drug sensitivity test by CD-DST. CD-DST was performed as described previously by Kobayashi $(22,23)$. Briefly, biopsied or surgically resected specimens were digested in dispersion collagenase enzyme and the dispersed cancer cells were incubated in a collagen coated flask. The viable cells alone adhering to the collagen gel layer were then collected and added to reconstructed Type I collagen solution (Cellmatrix type $\mathrm{CD}^{\mathrm{TM}}$; Niita Gelatin Inc., Yao, Japan). Three drops of these mixtures were placed in each well of a 6 -well multiplate and cisplatin $(0.2 \mu \mathrm{g} / \mathrm{ml})$ were then added to each well, and the plate was incubated for $24 \mathrm{~h}$. After removal of the medium containing cisplatin, each well was incubated with PCM-2 medium (Primaster, Niita gelatin Inc., Yao, Japan) for 7 days. Neural red was added to stain colonies in the collagen gel drops, which were finally fixed with formalin. The in vitro chemosensitivity effect of each chemoagent was expressed as a ratio of the surviving cells (T) of the total treated cells to that of the untreated cells (C). Originally, a sample with a ratio of $\mathrm{T}$ to $\mathrm{C}$ of $\leq 50 \%,>60 \%$, and from 51 to $60 \%$ was defined as in vitro sensitive, resistant, and borderline, respectively, but in the present study, the cutoff ratio was regarded as $60 \%$, thus, samples with a ratio of $\mathrm{T} / \mathrm{C}$ of $\leq 60 \%$ were considered as in vitro sensitive.

Cell culture and antibodies. Human HNSCC cell line Tb was obtained from Shanghai Ninth People's Hospital affiliated to Shanghai JiaoTong University School of Medicine (Shanghai, China) and cells were cultured in a complete medium (RPMI-1640 supplement with 10\% FCS). The antibodies toward Stat3, p-Stat3, Hes-1 and Notch1 were from Santa Cruz Biotechnology, Inc. (Santa Cruz, CA, USA).
Immunohistochemistry. Immunohistochemisty was performed using standard techniques. Antigen retrieval was performed by autoclaving. Incubation with $10 \%$ normal goat serum in phosphate-buffered saline was performed for $15 \mathrm{~min}$ to eliminate non-specific staining. Incubation with Stat 3 and Notch1 antibody respectively was carried out. Finally, sections were lightly counterstained with $10 \%$ Mayer's hematoxylin, dehydrated, mounted and observed. Staining was evaluated by a pathologist and an investigator blinded to diagnosis. Sections were classified + (focal and weak immunoreactivity), ++ (diffuse and weak or focal and intense immunoreactivity), +++ (diffuse and intense immunoreactivity).

Inhibition of Stat3 and Notch signaling and statistic analysis. Inhibition of Stat3 or Notch signaling with AG490 (Sigma) or the $\gamma$-secretase inhibitor N-[N-(3, 5-difluorophenacetyl-Lalanyl)]-S-phenylglycine t-butyl ester DAPT (Calbiochem), respectively, were described previously (24-29). In brief, AG490 was dissolved in DMSO to a stock concentration of $50 \mathrm{mM}$ and was diluted to the final concentration of $60 \mu \mathrm{M}$ with conventional culture medium just before use. DAPT was used at a final concentration of $1.0 \mu \mathrm{M}$ diluted in DMSO. DMSO group was mock treated with conventional medium containing the same concentration of DMSO carrier only. Control group was mock-treated with conventional medium only.

Western blotting. Western blotting was performed as described previously (18). The cells were lysed by $1 \mathrm{X}$ SDS lysis buffer (Tris-HCl, pH 6.8, 62.5 mM, 2\% SDS, 10\% glycerol) followed by centrifugation at $10,000 \mathrm{rpm}$ for 10 min at $4^{\circ} \mathrm{C}$. Equal amounts of cell lysates $(20-40 \mu \mathrm{g}$ total protein/lane) were loaded and separated by SDS-PAGE and proteins were transferred onto nitrocellulose membranes (Immobilon-P, Millipore, Billerica, MA, USA), probed with anti-Stat3 (1:1000), P-Stat3 (1:1000), Hes-1 (1:1000) and GAPDH (1:5000) followed by AP-conjugated secondary antibodies.

Statistics. The data were analyzed by SPSS 11.5 statistical package. Spearman rank correlation was used in Tables and Student's t-test was used in Fig. 3.

\section{Results}

Cisplatin resistance was associated with Stat3 and Notch1 expression. The specimens of 25 HNSCC patients were examined for cisplatin resistance by the CD-DST method. There were 8 patients sensitive to cisplatin and 17 showed resistances to it. Five of 8 patients $(62.5 \%)$ had weak Stat3 expression in the sensitive cases, while only one case $(5.88 \%)$ had weak Stat 3 expression in the 17 cisplatinresistant patients. Resistant patients showed 70.58\% (12/17), and sensitive cases $25 \%$ (2/8) of moderate Stat 3 expression, respectively. The statistical analysis showed that there was significant difference in expression level of Stat 3 between the cisplatin-sensitive and -resistant groups (Table I, $\mathrm{P}=0.014)$.

Furthermore, we detected the expression level of Notch1 in the same specimens of the 25 HNSCC patients. Six of 8 patients $(75 \%)$ had weak Notch1 expression in the sensitive 
Table I. Correlation between cisplatin resistance and Stat3 protein expression in HNSCC.

\begin{tabular}{lrrrc}
\hline & \multicolumn{4}{c}{ Stat3 } \\
\cline { 2 - 5 } Cisplatin sensitivity & + & ++ & +++ & Total \\
\hline Sensitivity & 5 & 2 & 1 & 8 \\
Resistance & 1 & 12 & 4 & 17 \\
Total & 6 & 14 & 5 & 25 \\
\hline
\end{tabular}

$\mathrm{r}_{\mathrm{s}}=0.484, \mathrm{P}=0.014$ (Spearman rank correlation).

cases, while only one case $(5.8 \%)$ had weak Notch1 expression in the 17 cisplatin-resistant patients. No patient showed intense Notch1 immunoreactivity in the sensitive group, however, there was $64.7 \%$ (11/17) of patients who had strong expression in the cisplatin-resistant group. The statistical analysis showed that there was a significant difference in the expression level of Notch1 between the cisplatin-sensitive and -resistant groups (Table II, $\mathrm{P}=0.000$ ).

The statistical analysis showed that there was a significant correlation of Stat 3 and Notch1 expression in the HNSCC patients $(\mathrm{P}=0.049)$. The expression of both proteins in each patient is summarized in Table III.

Pathological expression of Stat3 and Notch1 in HNSCC patients. Immunohistochemical staining of Stat3 in HNSCC patients are shown in Fig. 1, three levels of immunoreactivity was classified as described in methods. Normal squamous epithelial tissues have little Stat 3 expression as shown in Fig. 1A. Focal and weak immunoreactivity in cisplatin
Table II. Correlation between cisplatin resistance and Notch1 protein expression in HNSCC.

\begin{tabular}{lcccc}
\hline & \multicolumn{4}{c}{ Notch1 expression (cases) } \\
\cline { 2 - 5 } Cisplatin sensitivity & + & ++ & +++ & Total \\
\hline Sensitivity & 6 & 2 & 0 & 8 \\
Resistance & 1 & 5 & 11 & 17 \\
Total & 7 & 7 & 11 & 25 \\
\hline
\end{tabular}

$\mathrm{r}_{\mathrm{s}}=0.738, \mathrm{P}=0.000$ (Spearman rank correlation).

Table III. Correlation of Stat 3 and Notch1 expression in HNSCC.

\begin{tabular}{lcccc}
\hline & \multicolumn{4}{c}{ Stat3 expression } \\
\cline { 2 - 5 } Notch1 expression & + & ++ & +++ & Total \\
\hline+ & 1 & 6 & 0 & 7 \\
++ & 4 & 3 & 0 & 7 \\
+++ & 1 & 5 & 5 & 11 \\
Total & 6 & 14 & 5 & 25 \\
\hline
\end{tabular}

$\mathrm{r}_{\mathrm{s}}=0.397, \mathrm{P}=0.049$ (Spearman rank correlation).

sensitive HNSCC patient is shown in Fig. 1B and C showing focal and intense immunoreactivity, and Fig. 1D represent the diffuse and intense immunoreactivity, respectively, in
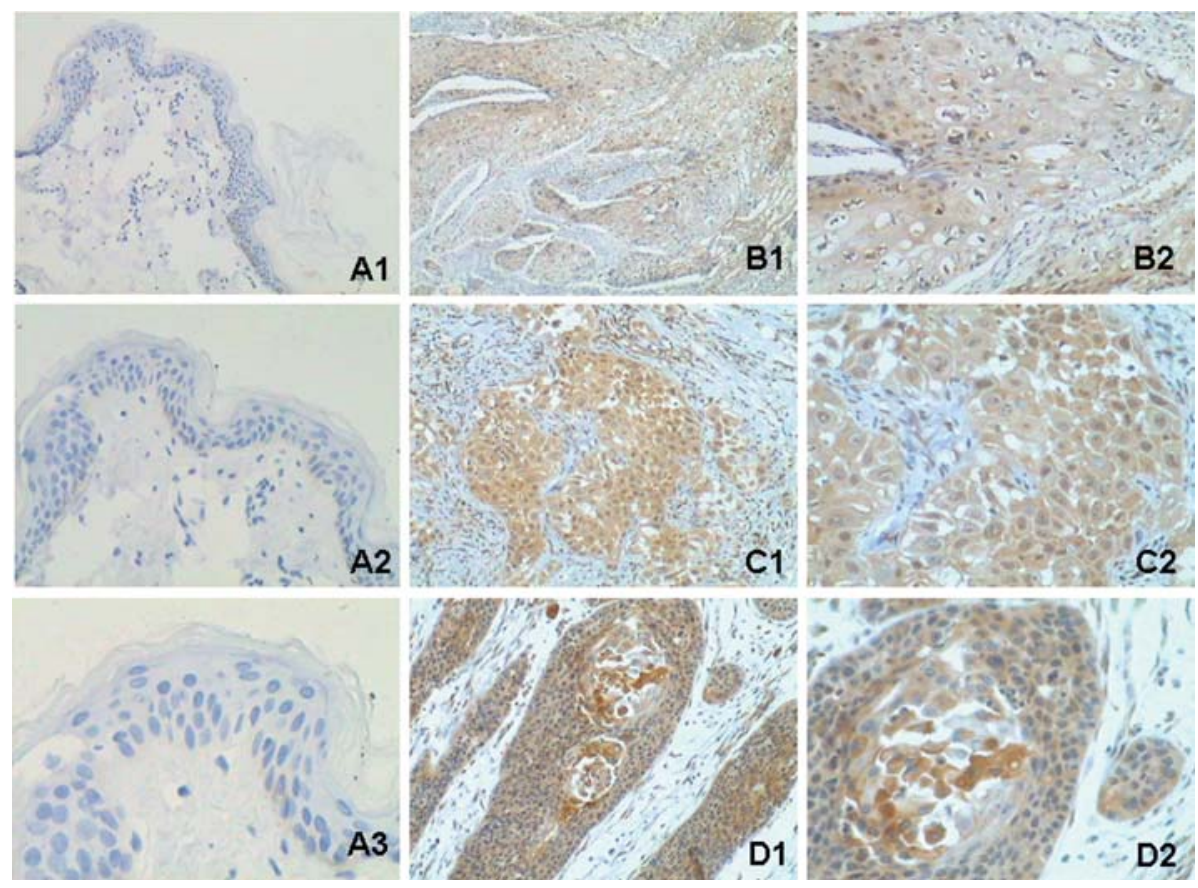

Figure 1. Expression of Stat3 protein in HNSCC patients. (A) Normal epithelial tissue. (B) Focal and weak expression of Stat3 protein in cisplatin-sensitive HNSCC patient. (C) Focal and intense Stat3 expression in cisplatin-resistant HNSCC patient. (D) Stat3 protein is strongly expressed in cisplatin-resistant HNSCC patient. Data show representative immunohistochemical staining. (x100: A1, B1, C1, D1; x200: A2, B2, C2, D2; x400: A3). 

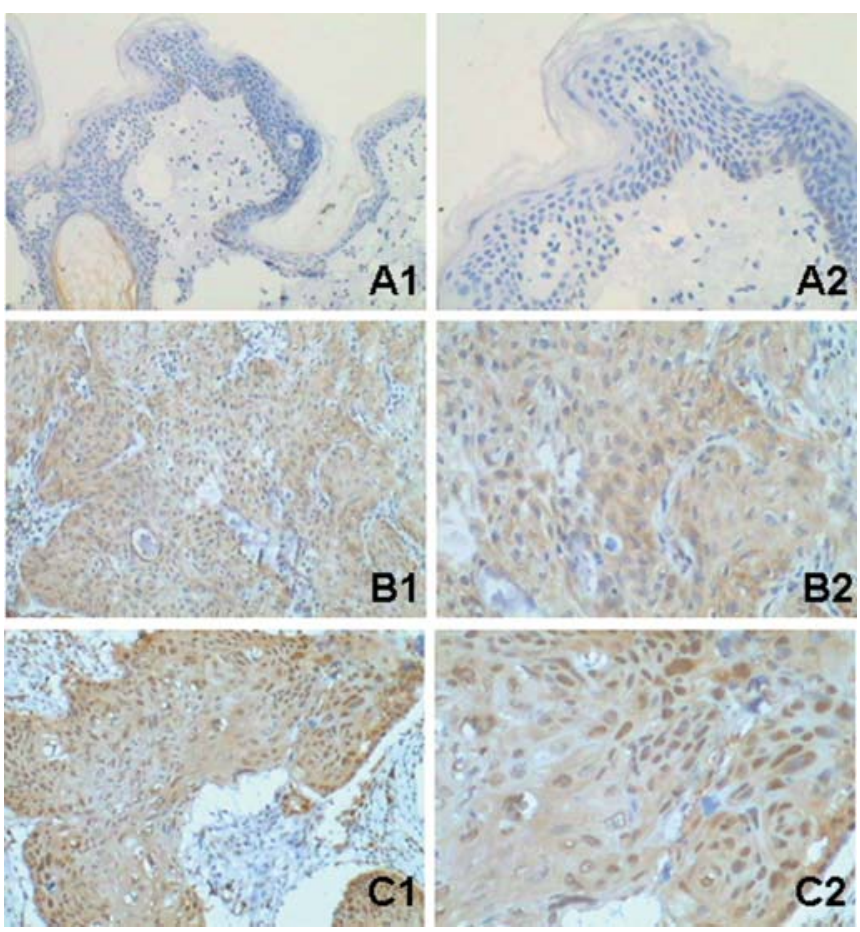

Figure 2. Expression of Notch1 protein in HNSCC patients. (A) Norma epithelial tissue. (B) Focal and weak expression of Stat3 protein in cisplatinsensitive HNSCC patient. (C) Focal and intense Stat3 expression in cisplatin-resistant HNSCC patient. Data show representative immunohistochemical staining (x100: A1, B1, C1, D1; x200: A2, B2, C2, D2).

A
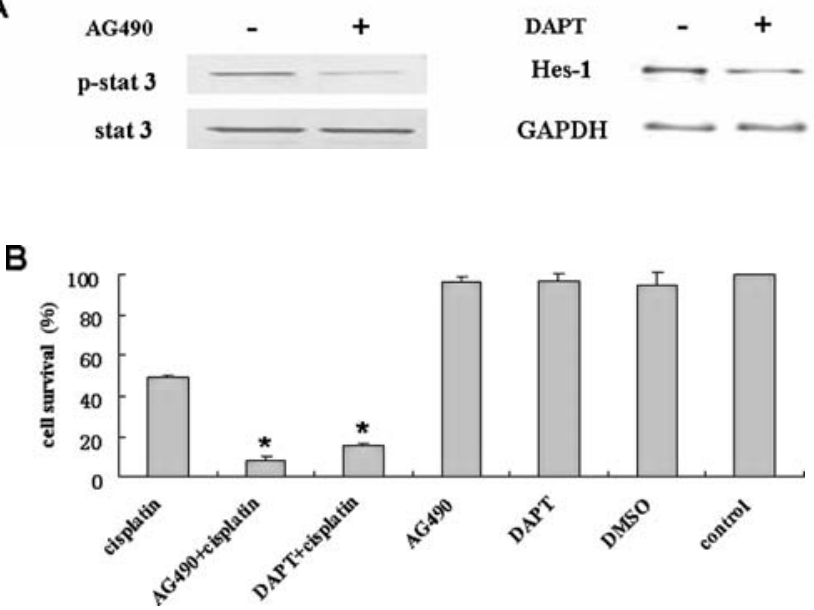

Figure 3. Inhibitor of Stat3 or Notch1 treatment increased Tb HNSCC cell sensitivity to cisplatin. (A) Tb cells were treated with $60 \mu \mathrm{M}$ of AG490 and $1.0 \mu \mathrm{M}$ of DAPT, respectively. Twenty-four hours later, cells were collected and the expression of phosphorylated Stat 3 and Hes-1 were detected by Western blotting. Expression of Stat 3 and GAPDH were used as control, respectively. (B) $\mathrm{Tb}$ cells were treated as indicated in the graph. After $24 \mathrm{~h}$ of treatment, cells were collected for the CD-DST test. Control, mock treatment with culture medium only. Data were from 3 independent experiments and analyzed by Student's t-test $\left({ }^{*} \mathrm{P}<0.05\right)$.

cisplatin-resistant HNSCC patients. We also detected the Notch1 expression in the same HNSCC patients. Different from the Stat 3 expression level, we did not find intense immunoreactivity of Notch 1 in the 8 cisplatin-sensitive HNSCC patients. Normal squamous epithelial tissues have little Notch1 expression as shown in Fig. 2A. Weak immunoreactivity in cisplatin-sensitive HNSCC patient is shown in Fig. 2B and $\mathrm{C}$ showing focal and intense immunoreactivity of Notch1 in the cisplatin resistance HNSCC patients.

Inhibitor treatment of Stat3 or Notch1 increased cisplatin sensitivity. As described above, cisplatin sensitivity of HNSCC patients was highly associated with the Stat 3 and Notch 1 expression. In order to confirm that Stat 3 and Notch1 are involved in the cisplatin sensitivity in HNSCC patients, we applied the selective inhibitor of Stat 3 signaling AG490 and Notch inhibitor DAPT, respectively. AG490 is a JAK2specific inhibitor and selectively inhibits Stat3 activity $(26,27)$. First, we detected the inhibitor function in cultured HNSCC Tb cells. With the treatment of $60 \mu \mathrm{M}$ of AG490 in Tb cells, phosphorylated Stat 3 was significantly decreased compared with the absence of AG490 group without affecting expression level of Stat3 (Fig. 3A). A major transcriptional downstream regulator of Notch1 pathway is the helix-loop-helix (HLH) transcription factor Hairy/Enhancer of Split 1 (Hes-1). Application of $1.0 \mu \mathrm{M}$ of DAPT ( $\gamma$-secretase inhibitor) in $\mathrm{Tb}$ cells led to reduced expression level of Hes-1 (Fig. 3A). Cultured $\mathrm{Tb}$ cells were divided into 5 groups, which were treated with $0.2 \mu \mathrm{g} / \mathrm{ml}$ cisplatin, $60 \mu \mathrm{M}$ AG490, combination of AG490 and cisplatin, DMSO and mock treatment, respectively, with culture medium was regarded as control. Cisplatin sensitivity detection by CD-DST method indicated that cell treatments with AG490 or DMSO were almost the same as mock control group. The ratio of combination group (AG490 and cisplatin) was $\sim 8.1 \%$, much lower than that of cisplatin group (48.6\%) (Fig. 3B, $\mathrm{P}=0.02$ ). Tb cells were also treated with $1.0 \mu \mathrm{M}$ of DAPT for inhibiting Notch signaling to confirm whether Notch1 is involved in cisplatin sensitivity. The ratio of combination group (DAPT and cisplatin) was $\sim 15.6 \%$, significantly lower than that of cisplatin group (Fig. $3 \mathrm{~B}, \mathrm{P}=0.037$ ). It suggested that inhibition of Stat3 signaling or Notch1 signaling caused the HNSCC cells to be more sensitive to cisplatin treatment.

\section{Discussion}

Stat 3 protein as a transcriptional activator and activates its target genes to affect a variety of critical cellular processes $(30-32)$. It has been reported that activation of Stat 3 was associated with drug resistance in ovarian cancer, hepatocellular carcinoma and non-small cell lung cancer (33-35). In the present study, we provided first evidence that high expression of Stat3 was correlated with cisplatin resistance in HNSCC patients. The precise mechanisms of Stat 3 involved in drug resistance remain unclear. It is already well known that Stat 3 activates C-Myc expression and the up-regulation of C-Myc induces DNA damage and genomic instability (36), so one possible mechanism is that the Stat3/C-Myc pathway might induce genetic alterations of chromosomes linking to drug resistance and clinical outcome (16). Chemoresistance was initially correlated to a reduced concentration of the drug via efflux pumps, to detoxification enzymes or to 
an enhanced DNA repair activity. It is now clear that tumor cells also escape cytotoxic treatments by reprogramming their survival pathways. It has been reported that Stat 3 is phosphorylated following genotoxic treatments such as irradiation or topoisomerase inhibition (37), this leads to another hypothesis that the transcriptional activity of Stat3 might be reprogrammed not only during the initial step of tumorigenesis but also during chemotherapy (16).

Notch signaling could participate in chemoresistance by protecting the cells from apoptosis, possibly as it activates targets which are involved in cellular survival, such as PI3K/Akt, Bcl-xl and survivin (38-40). Accumulating studies indicated that overexpression of Notch 1 increased the chemoresistance of $\mathrm{T}$ cells to etoposide, breast cancers to melphalan and mitoxantrone, cervical cancers to doxorubicin and lung cancers to cisplatin and paclitaxel $(38,39,41,42)$. In this study, we provided evidence that high expression of Notch1 was correlated with cisplatin resistance in HNSCC patients.

Although both Notch and JAK/STAT signaling pathways fulfill overlapping roles in growth and differentiation regulation, a physiologically crucial crosstalk between them was first demonstrated in 2004. Stat3 is activated in the presence of activated Notch, Notch1 target gene Hes1 associates with JAK2 and Stat3 to facilitate complex formation between JAK2 and Stat3, thus promoting Stat3 phosphorylation and activation (17). In the present study, we provided evidence that both high Stat 3 and Notch1 expression were associated with cisplatin resistance in HNSCC patients supporting the hypothesis that co-activation of Stat 3 and Notch1 by their crosstalk induces the reprogrammed survival pathways in HNSCC responsing to chemotherapy.

\section{Acknowledgements}

This study was supported by project grants from China 973 program (2006CB705600), National Scientific Foundation of China (30700253) and (30800355), China program of Changjiang scholar and innovative research team in University (IRT 0734), China project of SRF for ROCS SEM (2008101); 973 program (2009CB521705); 863 program (2006AA02A249).

\section{References}

1. Weaver A, Fleming S, Ensley J, Kish JA, Jacobs J, Kinzie J, Crissman J and Al-Sarraf M: Superior clinical response and survival rates with initial bolus of cisplatin and 120 hour infusion of 5-fluorouracil before definitive therapy for locally advanced head and neck cancer. Am J Surg 148: 525-529, 1984.

2. Rooney M, Kish J, Jacobs J, Kinzie J, Weaver A, Crissman J and Al-Sarraf $\mathrm{M}$ : Improved complete response rate and survival in advanced head and neck cancer after three-course induction therapy with 120-hour 5-FU infusion and cisplatin. Cancer 55: 1123-1128, 1985.

3. Cullen KJ, Newkirk KA, Schumaker LM, Aldosari N, Rone JD and Haddad BR: Glutathione S-transferase pi amplification is associated with cisplatin resistance in head and neck squamous cell carcinoma cell lines and primary tumors. Cancer Res 63: 8097-8102, 2003.

4. Jacobs C, Lyman G, Velez-Garcia E, Sridhar KS, Knight W, Hochster H, Goodnough LT, Mortimer JE, Einhorn LH and Schacter L: A phase III randomized study comparing cisplatin and fluorouracil as single agents and in combination for advanced squamous cell carcinoma of the head and neck. J Clin Oncol 10: 257-263, 1992.
5. Kartalou M and Essigmann JM: Mechanisms of resistance to cisplatin. Mutat Res 478: 23-43, 2001.

6. Giraud S, Bienvenu F, Avril S, Gascan H, Heery DM and Coqueret O: Functional interaction of STAT3 transcription factor with the coactivator NcoA/SRC1a. J Biol Chem 277: 8004-8011, 2002.

7. Giraud S, Hurlstone A, Avril S and Coqueret O: Implication of BRG1 and cdk9 in the STAT3-mediated activation of the p21waf1 gene. Oncogene 23: 7391-7398, 2004.

8. Nakashima K, Yanagisawa M, Arakawa H, Kimura N, Hisatsune T, Kawabata M, Miyazono K and Taga T: Synergistic signaling in fetal brain by STAT3-Smad1 complex bridged by p300. Science 284: 479-482, 1999.

9. Vultur A, Arulanandam R, Turkson J, Niu G, Jove R and Raptis L: Stat3 is required for full neoplastic transformation by the Simian Virus 40 large tumor antigen. Mol Biol Cell 16: 3832-3846, 2005.

10. Bromberg JF, Horvath CM, Besser D, Lathem WW and Darnell JE: Stat3 activation is required for cellular transformation by v-src. Mol Cell Biol 18: 2553-2558, 1998.

11. Zhang YW, Wang LM, Jove R and Vande Woude GF: Requirement of Stat3 signaling for HGF/SF-Met mediated tumorigenesis. Oncogene 21: 217-226, 2002.

12. Catlett-Falcone R, Landowski TH, Oshiro MM, Turkson J, Levitzki A, Savino R, Ciliberto G, Moscinski L, FernándezLuna JL, Nuñez G, Dalton WS and Jove R: Constitutive activation of Stat 3 signaling confers resistance to apoptosis in human U266 myeloma cells. Immunity 10: 105-115, 1999.

13. Haga S, Terui K, Zhang HQ, Enosawa S, Ogawa W, Inoue H, Okuyama T, Takeda K, Akira S, Ogino T, Irani K and Ozaki M: Stat3 protects against Fas-induced liver injury by redoxdependent and -independent mechanisms. J Clin Invest 112: 989-998, 2003.

14. Duan Z, Foster R, Bell DA, Mahoney J, Wolak K, Vaidya A, Hampel C, Lee $\mathrm{H}$ and Seiden MV: Signal transducers and activators of transcription 3 pathway activation in drug-resistant ovarian cancer. Clin Cancer Res 12: 5055-5063, 2006.

15. Dai Y, Rahmani M, Pei XY, Dent P and Grant S: Bortezomib and flavopiridol interact synergistically to induce apoptosis in chronic myeloid leukemia cells resistant to imatinib mesylate through both $\mathrm{Bcr} / \mathrm{Abl}-\mathrm{dependent}$ and -independent mechanisms. Blood 104: 509-518, 2004.

16. Barre B, Vigneron A, Perkins N, Roninson IB, Gamelin E and Coqueret O: The STAT3 oncogene as a predictive marker of drug resistance. Trends Mol Med 13: 4-11, 2007.

17. Kamakura S, Oishi K, Yoshimatsu T, Nakafuku M, Masuyama N and Gotoh Y: Hes binding to STAT3 mediates crosstalk between Notch and JAK-STAT signalling. Nat Cell Biol 6: 547-554, 2004.

18. Gu F, Hata R, Ma YJ, Tanaka J, Mitsuda N, Kumon Y, Hanakawa Y, Hashimoto K, Nakajima K and Sakanaka M: Suppression of Stat 3 promotes neurogenesis in cultured neural stem cells. J Neurosci Res 81: 163-171, 2005.

19. Nefedova Y, Cheng P, Alsina M, Dalton WS and Gabrilovich DI: Involvement of Notch-1 signaling in bone marrow stromamediated de novo drug resistance of myeloma and other malignant lymphoid cell lines. Blood 103: 3503-3510, 2004.

20. Nefedova Y, Sullivan DM, Bolick SC, Dalton WS and Gabrilovich DI: Inhibition of Notch signaling induces apoptosis of myeloma cells and enhances sensitivity to chemotherapy. Blood 111: 2220-2229, 2008.

21. Zhang ZP, Sun YL, Fu L, Gu F, Zhang L and Hao XS: Correlation of Notch 1 expression and activation to cisplatin-sensitivity of head and neck squamous cell carcinoma. Chin J Cancer 28: 100-103, 2009.

22. Kobayashi H: Development of a new in vitro chemosensitivity test using collagen gel droplet embedded culture and image analysis for clinical usefulness. Recent Results Cancer Res 161: 48-61, 2003.

23. Kobayashi H: Collagen gel droplet culture method to examine in vitro chemosensitivity. Methods Mol Med 110: 59-67, 2005.

24 .Yu LJ, Wu ML, Li H, Chen XY, Wang Q, Sun Y, Kong QY and Liu J: Inhibition of STAT3 expression and signaling in resveratrol-differentiated medulloblastoma cells. Neoplasia 10 : 736-744, 2008.

25. Huang C, Cao J, Huang KJ, Zhang F, Jiang T, Zhu L and Qiu ZJ: Inhibition of STAT3 activity with AG490 decreases the invasion of human pancreatic cancer cells in vitro. Cancer Sci 97: 1417-1423, 2006. 
26. Wu MH, Chen XY and Cai KR: Effects of a JAK inhibitor, AG490, on proliferation and apoptosis of human nasopharyngeal carcinoma cell line CNE-2Z. Chin J Cancer 28: 24$28,2009$.

27. Shim SH, Sung MW, Park SW and Heo DS: Absence of STAT1 disturbs the anticancer effect induced by STAT3 inhibition in head and neck carcinoma cell lines. Int J Mol Med 23: 805-810, 2009.

28. Balint K, Xiao M, Pinnix CC, Soma A, Veres I, Juhasz I, Brown EJ, Capobianco AJ, Herlyn M and Liu ZJ: Activation of Notch1 signaling is required for beta-catenin-mediated human primary melanoma progression. J Clin Invest 115: 3166-3176, 2005.

29. van den Brandt J, Voss K, Schott M, Hunig T, Wolfe MS and Reichardt HM: Inhibition of Notch signaling biases rat thymocyte development towards the NK cell lineage. Eur J Immunol 34: 1405-1413, 2004.

30. Akira S: Roles of STAT3 defined by tissue-specific gene targeting. Oncogene 19: 2607-2611, 2000.

31. Alonzi T, Middleton G, Wyatt S, Buchman V, Betz UA, Muller W, Musiani P, Poli V and Davies AM: Role of STAT3 and PI 3-kinase/Akt in mediating the survival actions of cytokines on sensory neurons. Mol Cell Neurosci 18: 270-282, 2001.

32. Bonni A, Sun Y, Nadal-Vicens M, Bhatt A, Frank DA, Rozovsky I, Stahl N, Yancopoulos GD and Greenberg ME: Regulation of gliogenesis in the central nervous system by the JAK-STAT signaling pathway. Science 278: 477-483, 1997.

33. Duan Z, Ames RY, Ryan M, Hornicek FJ, Mankin H and Seiden MV: CDDO-Me, a synthetic triterpenoid, inhibits expression of IL-6 and Stat3 phosphorylation in multi-drug resistant ovarian cancer cells. Cancer Chemother Pharmacol 63 : 681-689, 2009.

34. Lau CK, Yang ZF, Lam SP, Lam CT, Ngai P, Tam KH, Poon RT and Fan ST: Inhibition of Stat 3 activity by YC-1 enhances chemo-sensitivity in hepatocellular carcinoma. Cancer Biol Ther 6: 1900-1907, 2007
35. Ikuta K, Takemura K, Kihara M, Nishimura M, Ueda N, Naito S, Lee E, Shimizu E and Yamauchi A: Overexpression of constitutive signal transducer and activator of transcription 3 mRNA in cisplatin-resistant human non-small cell lung cancer cells. Oncol Rep 13: 217-222, 2005.

36. Vafa O, Wade M, Kern S, Beeche M, Pandita TK, Hampton GM and Wahl GM: c-Myc can induce DNA damage, increase reactive oxygen species, and mitigate p53 function: a mechanism for oncogene-induced genetic instability. Mol Cell 9: 1031-1044, 2002.

37. Lim CP and Cao X: Serine phosphorylation and negative regulation of Stat3 by JNK. J Biol Chem 274: 31055-31061, 1999.

38. Nair P, Somasundaram K and Krishna S: Activated Notch1 inhibits p53-induced apoptosis and sustains transformation by human papillomavirus type 16 E6 and E7 oncogenes through a PI3K-PKB/Akt-dependent pathway. J Virol 77: 7106-7112, 2003.

39. Sade H, Krishna S and Sarin A: The anti-apoptotic effect of Notch-1 requires p56lck-dependent, Akt/PKB-mediated signaling in T cells. J Biol Chem 279: 2937-2944, 2004.

40. Wang Z, Banerjee S, Li Y, Rahman KM, Zhang Y and Sarkar FH: Down-regulation of notch-1 inhibits invasion by inactivation of nuclear factor-kappaB, vascular endothelial growth factor, and matrix metalloproteinase-9 in pancreatic cancer cells. Cancer Res 66: 2778-2784, 2006.

41. Mungamuri SK, Yang X, Thor AD and Somasundaram K: Survival signaling by Notch1: mammalian target of rapamycin (mTOR)-dependent inhibition of p53. Cancer Res 66: 4715-4724, 2006.

42. Stylianou S, Clarke RB and Brennan K: Aberrant activation of notch signaling in human breast cancer. Cancer Res 66: 1517-1525, 2006. 